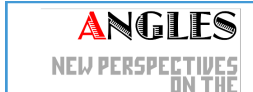
ANELOPHONE WORLD

\section{Angles}

New Perspectives on the Anglophone World

$8 \mid 2019$

Neoliberalism in the Anglophone World

\title{
Graphic Interlude: Neoliberalism in the Anglophone World
}

\section{Eduardo Bardi}

\section{Q OpenEdition \\ 1 Journals}

\section{Electronic version}

URL: https://journals.openedition.org/angles/607

DOI: $10.4000 /$ angles. 607

ISSN: 2274-2042

\section{Publisher}

Société des Anglicistes de l'Enseignement Supérieur

\section{Electronic reference}

Eduardo Bardi, "Graphic Interlude: Neoliberalism in the Anglophone World", Angles [Online], 8| 2019, Online since 01 April 2019, connection on 08 June 2022. URL: http://journals.openedition.org/angles/ 607 ; DOI: https://doi.org/10.4000/angles.607

This text was automatically generated on 8 June 2022.

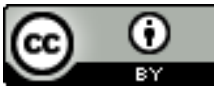

Angles est mise à disposition selon les termes de la Licence Creative Commons Attribution 4.0 International. 


\section{Graphic Interlude: Neoliberalism in the Anglophone World}

Eduardo Bardi

Figure 1. Common Agenda Poster

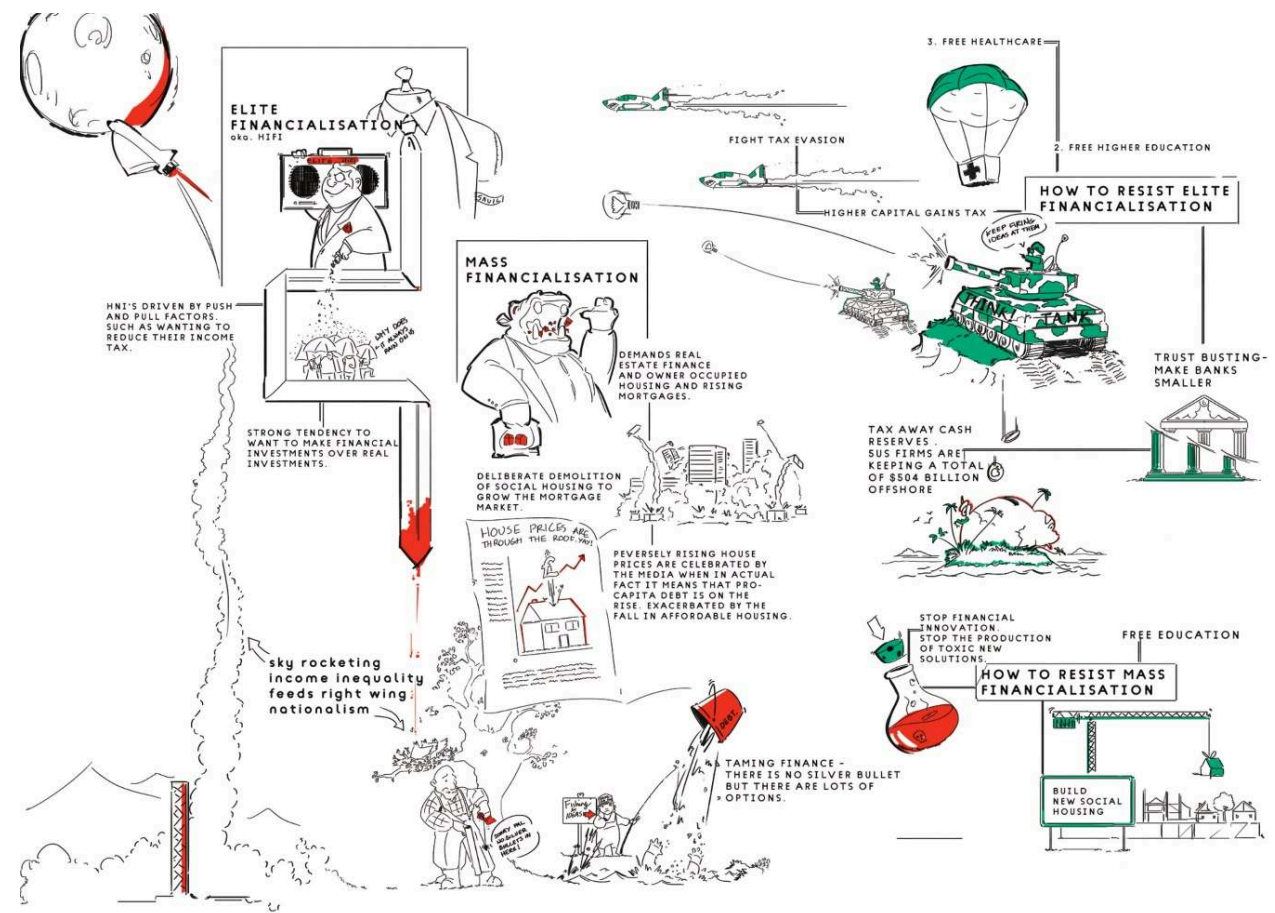

Source: Eduardo Bardi. 
Figure 2. Elite Financialisation

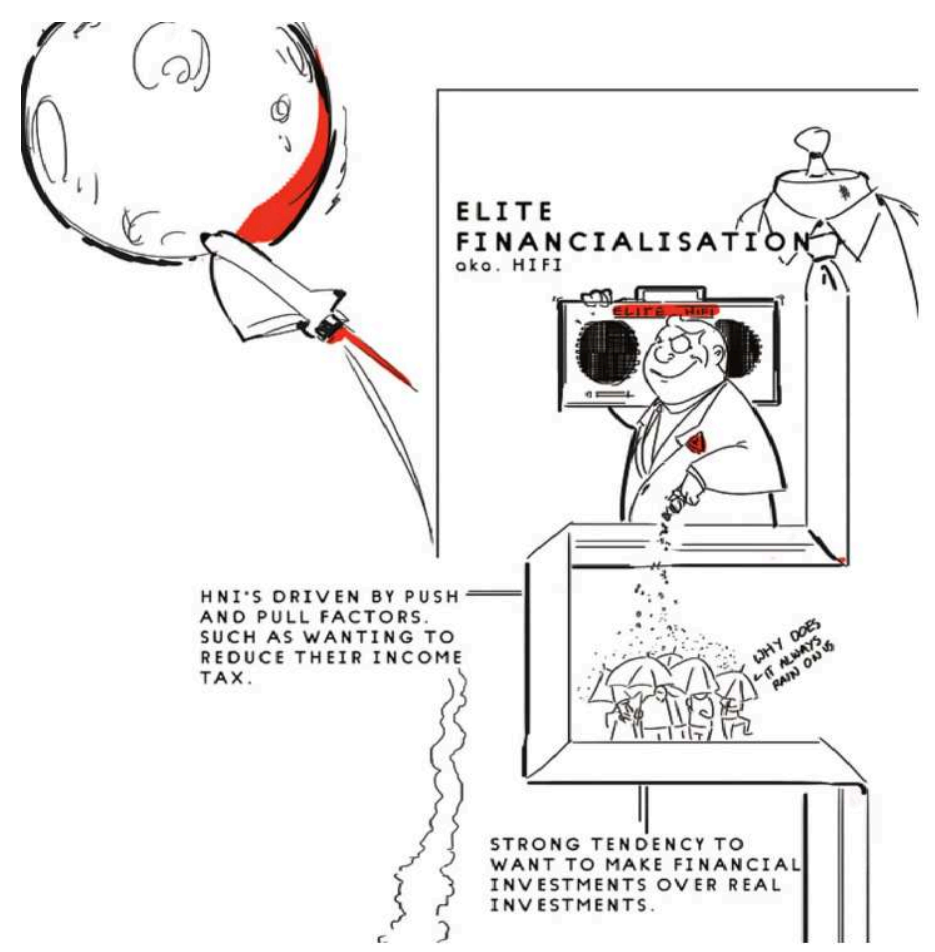

Source: Eduardo Bardi.

Figure 3. Lived Experience of Austerity

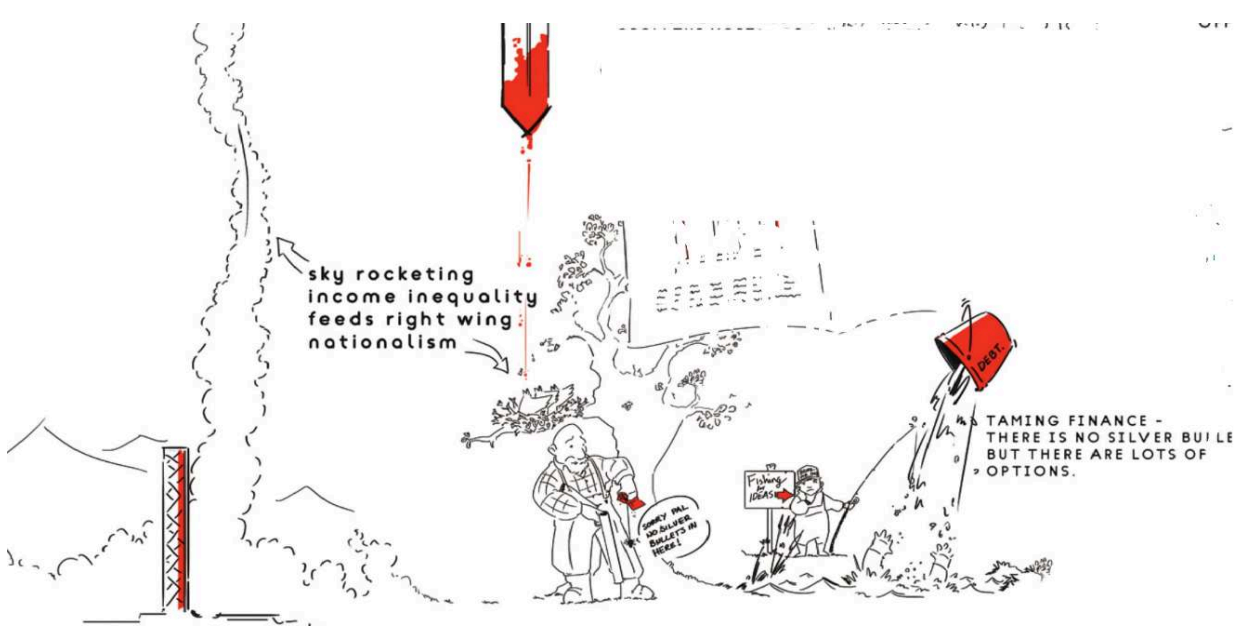

Source: Eduardo Bardi. 
Figure 4. Mass Financialisation

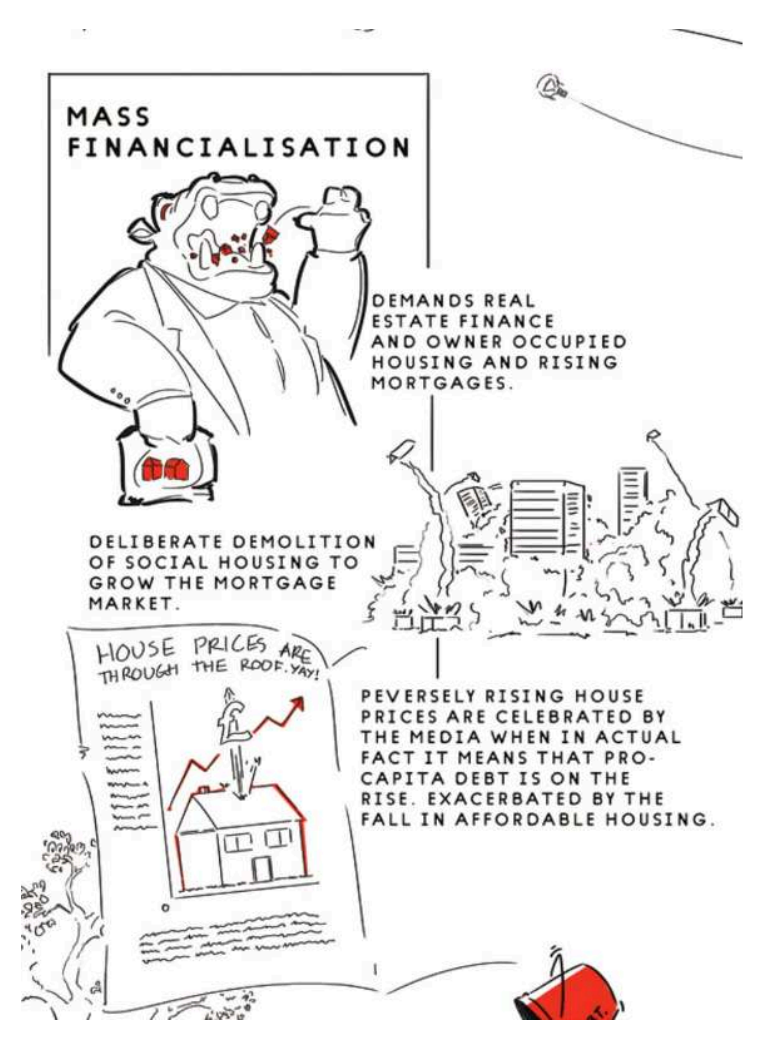

Source: Eduardo Bardi.

Figure 5. Resistance to Elite Financialisation

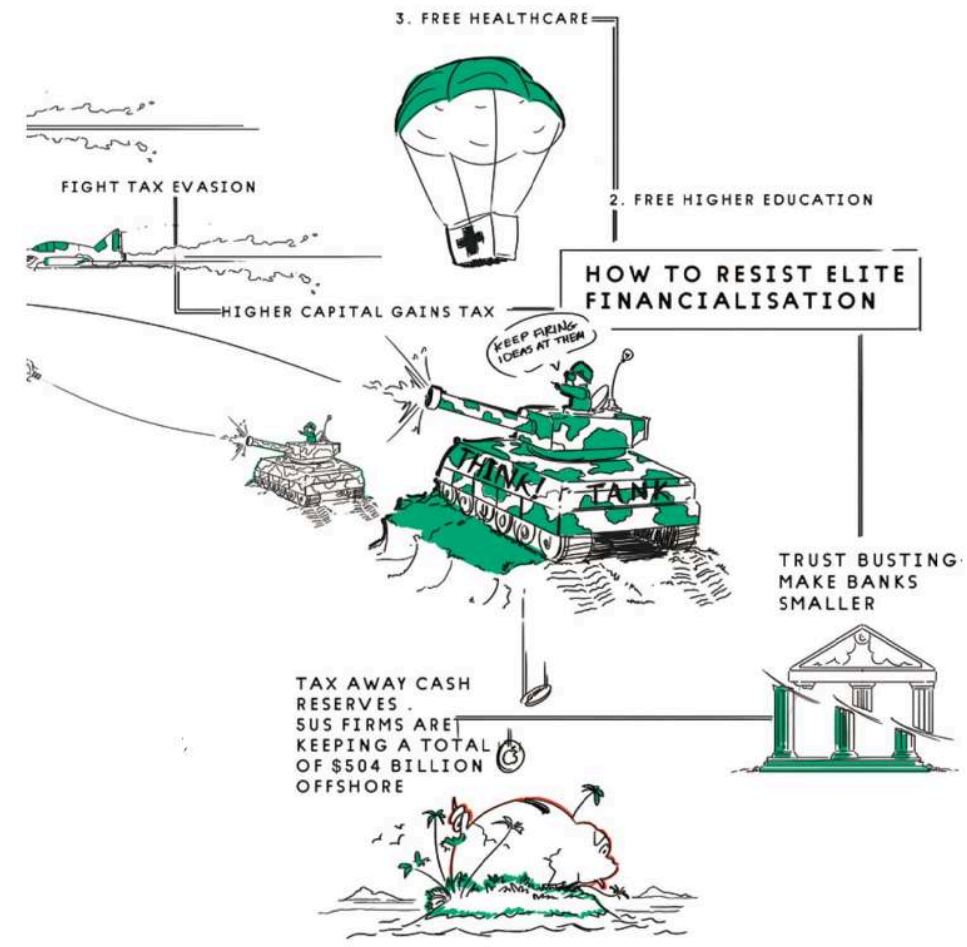

Source: Eduardo Bardi. 
Figure 6. Resistance to Elite Financialisation 2

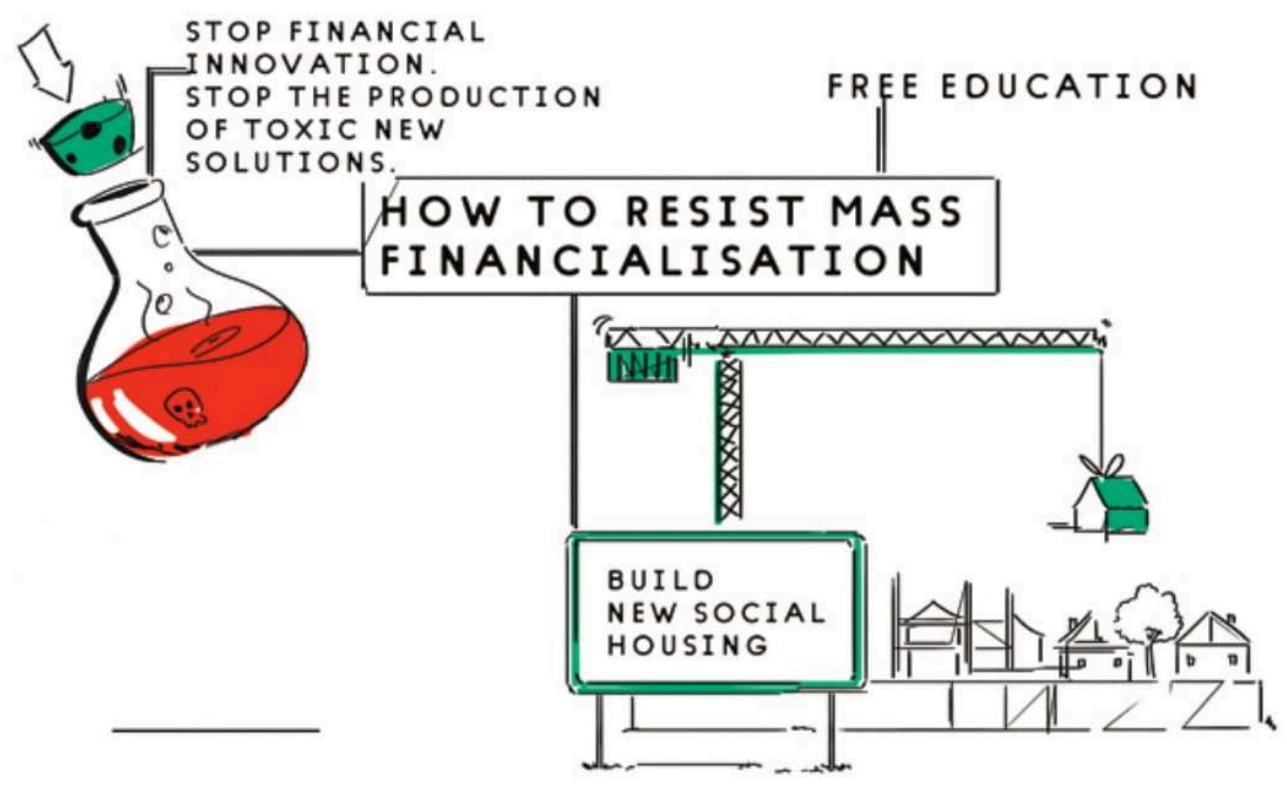

\section{ABSTRACTS}

This graphic interlude features a poster illustrating this issue's topic: neoliberalism, the workings of financialisation and means of resistance against this system.

Cet interlude graphique est composé d'une affiche qui illustre le thème de ce numéro, le néolibéralisme. Il détaille les mécanismes de financiarisation du monde et les moyens de résistance.

\section{INDEX}

Mots-clés: néolibéralisme, services financiers, économie, politique, résistance Keywords: neoliberalism, financial services, economics, politics, resistance 


\section{AUTHOR}

\section{EDUARDO BARDI}

Eduardo Bardi is a creative artist who works on visual communication, advertising, digital design, corporate and brand identity projects. His website: https://www.eduardobardi.com/ Contact: eduardo.b.bardi[at]gmail.com 